\title{
HEAT TRANSFER TO NON-NEWTONIAN FLUIDS IN AN AGITATED VESSEL*
}

\author{
Nobuo MITSUISHI and Yoshio MIYAIRI** \\ Department of Nuclear Engineering, Kyushu University, \\ Fukuoka, Japan
}

\begin{abstract}
This study deals with non-Newtonian heat transfer with several types of agitators: (1) an agitator with a 2-bladed paddle, (2) an agitator with a helical screw in a draft tube, (3) an agitator with a helical ribbon. The non-Newtonian fluids tested consisted of various concentrations of aqueous solutions of CMC, HEC, PO and SPA. The threeconstant Ellis model was used to characterize the non-Newtonian fluids. By using the non-Newtonian viscosities proposed in this paper, the correlations for non-Newtonian heat transfer in the three types of agitators agree very well with those for Newtonian heat transfer. These experimental results may be valuable in industrial design since only a limited number of such studies are available.
\end{abstract}

\section{Introduction}

It is very difficult to correlate the experimental data of non-Newtonian heat transfer in an agitated vessel. Although various correlations of experimental results have been proposed, they may not be appropriate for industrial design due to the inadequacy of the model of non-Newtonian viscosities used. There are many nonNewtonian fluids whose viscosity cannot be expressed by a power law model. Non-Newtonian fluids of relatively low viscosity have been used in most previous studies. In the correlation of heat transfer, some authors applied the viscosity which was used in power correlation $^{8,10,11)}$. Others neglected non-Newtonian properties in order to evaluate a characteristic apparent shear rate $\gamma^{3,8,11)}$.

In the present paper, heat transfer to highly viscous non-Newtonian fluids in an agitated vessel is phenomenologically and semi-theoretically correlated. The three-constant Ellis model is used as a nonNewtonian model, and the experimental data for the three types of stirrers investigated are well correlated by the models presented here.

\section{Correlations of Heat Transfer in an Agitated Vessel}

The experiments were performed with three types of agitators: (1) an agitator with 2-bladed paddle (cooling from the impeller and heating from a jacketed vessel wall), (2) an agitator with a helical screw in a

\footnotetext{
* Received on February 19, 1973

Presented partly at the Local Meeting of the Soc. of Chem.

Engrs., Japan, at Fukuoka, Sept. 17, 1970

** Mitsubishi Heavy Industries, Ltd.

T812 福岡市東区箱崎町

九州大学工学部応用原子核工学教室 三石信雄
}

draft tube (cooling from a draft tube and heating from a jacketed vessel wall) (3) an agitator with a helical ribbon (cooling from a helical ribbon and heating from a jacketed vessel wall). The experimental data may be correlated by the following expression ${ }^{12)}$.

$$
N u=D_{l} h / \lambda=\dot{C}\left(\operatorname{Re}^{*}\right)^{\alpha}\left(\operatorname{Pr}^{*}\right)^{1 / 3}\left(V i s^{*}\right)^{-0.14}
$$

where

$$
\begin{aligned}
R e^{*} & =\rho N d^{2} / \mu^{*} \\
\operatorname{Pr}^{*} & =C_{p} \mu^{*} / \lambda \\
V i s^{*} & =\mu_{s}^{*} / \mu^{*}
\end{aligned}
$$

$\mu^{*}$ is the non-Newtonian viscosity. In our previous paper, Newtonian heat transfer was correlated by Eq. $(1)^{7)}$. For non-Newtonian heat transfer, however, the choice of $\mu^{*}$ presents difficulties.

\section{Non-Newtonian Viscosity in an Agitated Vessel}

Since there are a lot of non-Newtonian fluids which cannot be expressed by a power law model, the threeconstant Ellis model was used for the non-Newtonian fluids.

$$
\begin{aligned}
\tau & =-\eta \Delta \\
\frac{1}{\eta} & =\frac{1}{\eta_{0}}\left(1+\left|\frac{\sqrt{\frac{1}{2}(\tau: \tau)}}{\tau_{1 / 2}}\right|^{\alpha-1}\right)
\end{aligned}
$$

\section{1 An agitator with 2-bladed paddle}

To evaluate non-Newtonian viscosity at the jacketed vessel wall in an agitator with 2-bladed paddle, we considered the behavior of an Ellis model fluid between two concentric cylinders, as shown in Fig. 1, as a simplified representation of the complicated fluid flow in the agitated vessel. Solving the equation of motion leads to the following relation between angular velocity 


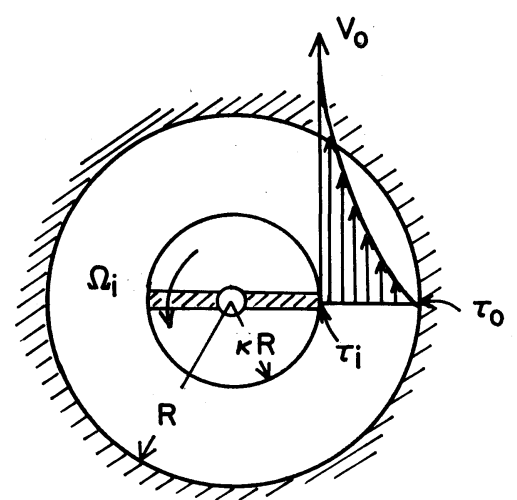

Fig. 1 Tangential flow profile between two coaxial cylinders

$\Omega_{i}$ and the shearing stress exerted on the wall of an outer cylinder.

$$
\Omega_{i}^{*}=\frac{T_{0}^{*}}{2}\left(\frac{1}{\kappa^{2}}-1\right)+\frac{\left(T_{0}^{*}\right)^{\alpha}}{2 \alpha}\left(\frac{1}{\kappa^{2 \alpha}}-1\right)
$$

where

$$
\Omega_{i}^{*} \equiv \Omega_{i}\left(\frac{\eta_{0}}{\tau_{1 / 2}}\right), \quad T_{0}^{*} \equiv \tau_{0} / \tau_{1 / 2}
$$

By defining a friction factor and a Reynolds number as follows:

$$
f_{0}=\frac{\text { shearing stress on an outer cylinder }}{\text { kinetic energy of an inner cylinder }}=\frac{\tau_{0}}{\frac{1}{2} \rho\left(\frac{2 \kappa R \Omega_{i}}{2 \pi}\right)^{2}}
$$

$$
R e=\frac{\rho\left(\Omega_{i} / 2 \pi\right)(2 \kappa R)^{2}}{\mu}
$$

the following equation for Newtonian fluid flow in a concentric annulus is obtained:

$$
f_{0}=\frac{1}{R e}(8 \pi)\left(\frac{\kappa^{2}}{1-\kappa^{2}}\right)
$$

Where $\kappa$ is the diameter ratio of the inner and outer cylinders. If the Reynolds number is defined by Eq. (10) for the Ellis model; the following expressions are obtained from Eqs. (7), (9) and (11).

$$
\begin{aligned}
& R e_{\tan }^{*}=\rho N d^{2} / \mu_{\tan }^{*} \\
& \mu_{\text {tan }}^{*}=\frac{\eta_{0}}{2} \frac{\left(1-\kappa^{2}\right) / \kappa^{2}}{\frac{1}{2}\left(\frac{1}{\kappa^{2}}-1\right)+\frac{\left(T_{0}^{*}\right)^{\alpha-1}}{2 \alpha}\left(\frac{1}{\kappa^{2 \alpha}}-1\right)}
\end{aligned}
$$

Eqs.(12) and (13) define a modified Reynolds number and a non-Newtonian viscosity for tangential flow between two vertical coaxial cylinders, and we have used these definitions to correlate data for heat transfer to the vessel wall of an agitator with a paddle or anchor since in these cases the tangential flow has a significant effect on the heat transfer.

For highly viscous fluids, almost all the energy of agitation may be dissipated near the impeller wall, and, since the fluid flow near the impeller is closely related to the power consumption and heat transfer, the following non-Newtonian viscosity for power con-
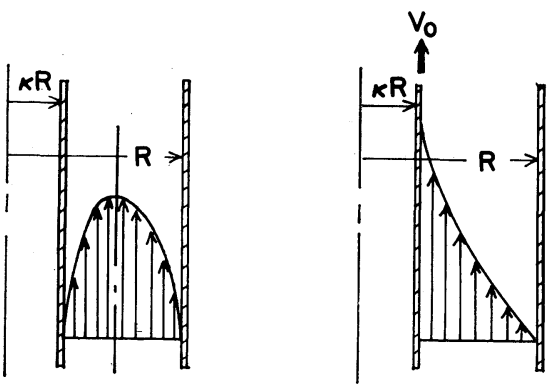

(a) Fluid flow profile due to pressure difference

(b) Fluid flow profile due to inner wall motion

Fig. 2 Axial flow profile in a concentric annulus

sumption was employed in correlating data for heat transfer to the impeller wall ${ }^{6)}$.

$$
\mu_{\mathrm{power}}^{*}=\eta_{0} /\left[1+\frac{4}{\alpha+3}\left\{T_{w}\left(\alpha, 8 N \frac{\eta_{0}}{\tau_{1 / 2}}\right)\right\}^{\alpha-1}\right]
$$

\section{2 An agitator with a helical screw in a draft tube}

For this type of agitator, we considered the axial flow of an Ellis model fluid in a concentric annulus as the model of flow (see Fig. 2(a)). Initially, for the laminar flow of the Ellis model fluid in a circular tube, the relation between the average fluid velocity $\langle v\rangle$ and the shearing stress $\tau_{w}$ at the wall is given by the following equation.

where

$$
\Gamma=T_{w}\left(1+\frac{4}{\alpha+3} T_{w}^{\alpha-1}\right)
$$

$\Gamma \equiv\left(\frac{4 Q}{\pi R^{3}}\right)\left(\frac{\eta_{0}}{\tau_{1 / 2}}\right)=\left(\frac{4<v>}{R}\right)\left(\frac{\eta_{0}}{\tau_{1 / 2}}\right), \quad T_{w}=\tau_{w} / \tau_{1 / 2}$

For a Newtonian fluid in a circular tube, the friction factor:

$$
f_{w}=2 \tau_{w} / \rho<v>^{2}
$$

and the Reynolds number are related as follows:

$$
f_{w}=16 / R e
$$

and the following expression may be obtained by the method described in 2.1 using Eq.(18).

$$
\begin{aligned}
R e_{\mathrm{pipe}}^{*} & =\frac{D<v>\rho}{\mu_{\mathrm{pipe}}^{*}} \\
\mu_{\mathrm{pipe}}^{*} & =\frac{\eta_{0}}{1+\frac{4}{\alpha+3}\left\{T_{w}\left(\alpha, \frac{8<v>}{D} \frac{\eta_{0}}{\tau_{1 / 2}}\right)\right\}^{\alpha-1}}
\end{aligned}
$$

To apply Eq.(19) to the fluid flow in an agitator, we introduce $\rho N d^{2}$ for $D<v>\rho$ in the equation, and for the diameter $D$, the following hydraulic equivalent diameter for the axial flow in a concentric annulus:

$$
\begin{aligned}
D_{e} & =4 r_{h} / \phi(\kappa) \\
\phi(\kappa) & =\frac{(1-\kappa)^{2}}{\frac{1-\kappa^{4}}{1-\kappa^{2}}-\frac{1-\kappa^{2}}{\ln (1 / \kappa)}}
\end{aligned}
$$


The modified Reynolds number and non-Newtonian viscosity are expressed as

$$
\begin{aligned}
R e_{a x}^{*} & =\rho N d^{2} / \mu_{a x}^{*} \\
\mu_{a x}^{*} & =\frac{\eta_{0}}{1+\frac{4}{\alpha+3}\left\{T_{w}\left(\alpha, \frac{8 N d}{D_{e}} \frac{\eta_{0}}{\tau_{1 / 2}}\right)\right\}^{\alpha-1}}
\end{aligned}
$$

This approach may be applied in correlating data for heat transfer to the vessel walls and to the outer wall of a draft tube in which the flow is primarily similar to the fluid flow in an annulus. Applying the method in 2.1 to the flow shown in Fig. 2(b) gives the following expression:

$$
V_{0}=T_{R}\left[\frac{1}{2} \ln (1 / \kappa)+\frac{1}{2(\alpha-1)}\left(T_{R}\right)^{\alpha-1}\left(\frac{1}{\kappa^{\alpha-1}}-1\right)\right]
$$

where

$$
V_{0} \equiv \frac{v_{0}}{2 R} \frac{\eta_{0}}{\tau_{1 / 2}}, \quad T_{R} \equiv \tau_{R} / \tau_{1 / 2}
$$

The modified Reynolds number and a modified viscosity are given by

$$
\begin{aligned}
R e_{a x^{\prime}}^{*} & =\rho N d^{2} / \mu_{a x^{\prime}}^{*} \\
\mu_{a x^{\prime}}^{*} & =\frac{\eta_{0}}{2} \\
& \times \frac{\ln (1 / \kappa)}{\frac{1}{2} \ln \left(\frac{1}{\kappa}\right)+\frac{1}{2(\alpha-1)}\left\{T_{R}\left(\alpha, V_{0}\right)\right\}^{\alpha-1}\left(\frac{1}{\kappa^{\alpha-1}}-1\right)}
\end{aligned}
$$

This approach may be applied to the flow behavior near the wall of a helical screw.

\section{3 An agitator with a helical ribbon}

In the case of small clearance, the flow between a vessel wall and a ribbon may be approximated by considering the flow between two parallel flat plates. In the case of vertical fluid flow under the condition of complete slip on the helical ribbon, the fluid velocity is given by $\pi N p(=\pi N d$; with the helical ribbon used in this experiment). For completely adhesive flow on the ribbon wall, it is $\pi N d$ in tip section. As indicated in Fig. 3, the fluid velocity is generally represented by a vector from $\mathrm{A}$ to an arbitrary point on the line B, C and lies between the following two values:

$$
\begin{array}{r}
\frac{\pi N d}{\sqrt{2}} \leq \text { the fluid velocity at the tip section } \\
\text { of the helical ribbon } \leq \pi N d .
\end{array}
$$

The shear rate at the vessel wall seems to lie within the following range,

$$
\sqrt{2} \pi N\left(\frac{d}{D-d}\right) \leq \dot{r} \leq 2 \pi N\left(\frac{d}{D-d}\right)
$$

The following expression correlated very well with our experimental data,

$$
\dot{\gamma}=\sqrt{2} \pi N\left(\frac{d}{D-d}\right)
$$

\begin{tabular}{|c|c|c|c|c|}
\hline No. & Impeller & $\begin{array}{l}\text { Wall of heat } \\
\text { transfer }\end{array}$ & $\begin{array}{l}\text { Non- Cha } \\
\text { Newtonian leng } \\
\text { viscosity Nuss }\end{array}$ & $\begin{array}{l}\text { acteristic } \\
\text { h used in } \\
\text { lt number }\end{array}$ \\
\hline 1 & $\begin{array}{l}\text { 2-bladed } \\
\text { paddle }\end{array}$ & $\begin{array}{l}\text { Jacketed vessel wall } \\
\text { Impeller wall }\end{array}$ & $\begin{array}{l}\mathrm{Eq} \cdot(13) \\
\mathrm{Eq} \cdot(14)\end{array}$ & $\begin{array}{l}D \\
d\end{array}$ \\
\hline 2 & $\begin{array}{l}\text { Helical } \\
\text { screw in } \\
\text { a draft } \\
\text { tube }\end{array}$ & $\begin{array}{l}\text { Jacketed vessel wall } \\
\text { Inner wall of a } \\
\text { draft tube } \\
\text { Outer wall of a draf } \\
\text { tube }\end{array}$ & $\begin{array}{l}\mathrm{Eq} \cdot(24) \\
\mathrm{Eq} \cdot(28) \\
\mathrm{Eq} \cdot(24)\end{array}$ & $\begin{array}{l}D_{d i} \\
D_{d o}\end{array}$ \\
\hline 3 & $\begin{array}{l}\text { Helical } \\
\text { ribbon }\end{array}$ & $\begin{array}{l}\text { Jacketed vessel wall } \\
\text { Impeller wall }\end{array}$ & $\begin{array}{l}\text { Flow curve and } \\
\text { Eq. }(30) \\
\text { Flow curve and } \\
\text { Eq. }(31)\end{array}$ & $\begin{array}{l}D \\
d\end{array}$ \\
\hline
\end{tabular}

The non-Newtonian viscosity at the vessel wall may be estimated from a flow curve using the $\dot{\gamma}$ value by Eq. (30). It is very difficult, however, to estimate the nonNewtonian viscosity at the helical ribbon wall since the
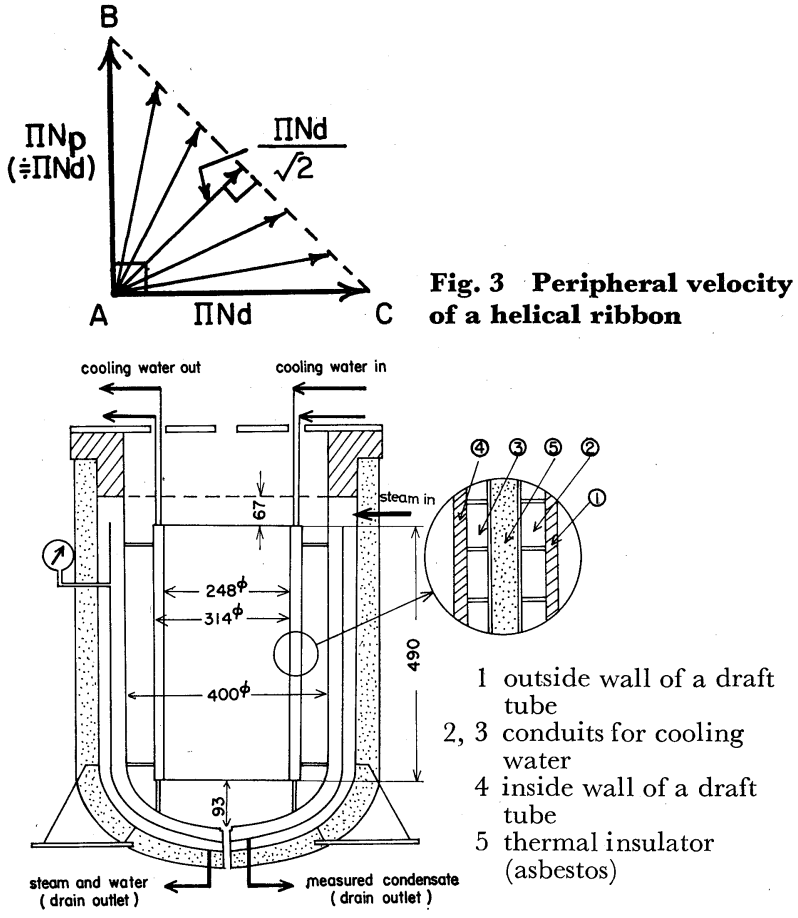

Fig. 4 Experimental apparatus

Table 1 Estimation of non-Newtonian viscosities for

heat transfer correlations

helical ribbon has four side walls. Hence, the present experimental data were correlated by an equation obtained by multiplying Eq.(30) by a factor $\beta$. It was found that $\beta \doteqdot 0.5$ gave the best correlation for the experimental data. The non-Newtonian viscosity may be estimated from the flow curve using the following expression,

$$
\dot{\gamma}=\frac{\pi N}{\sqrt{2}}\left(\frac{d}{D-d}\right)
$$

Table 1 gives the methods for estimating values of non-Newtonian viscosities for heat transfer correlations.

\section{Experimental Work}

\section{1 Experimental apparatus and procedure}

Figure 4 shows an agitated vessel with a draft tube as used in the present experiments. The agitated vessel is the same as in the authors' previous paper?). Figure 5 shows the helical ribbon used in the present work 
Table 2 Agitator dimensions

\begin{tabular}{|c|c|c|c|c|}
\hline Vessel diameter & $40 \mathrm{~cm}$ & \multirow[b]{2}{*}{ Impeller diameter } & 2-bladed paddles & $\begin{array}{l}20 \mathrm{~cm} \\
32.2 \mathrm{~cm}\end{array}$ \\
\hline Гype of bottom & dished & & $\begin{array}{l}\text { helical screw } \\
\text { helical ribbon }\end{array}$ & $\begin{array}{l}21 \mathrm{~cm} \\
38 \mathrm{~cm}\end{array}$ \\
\hline Liquid height & $65 \mathrm{~cm}$ & \multirow{2}{*}{ Draft tube } & inner diameter & $24.8 \mathrm{~cm}$ \\
\hline Impeller rotation & $10-150 \mathrm{rpm}$ & & outer diameter & $31.4 \mathrm{~cm}$ \\
\hline
\end{tabular}

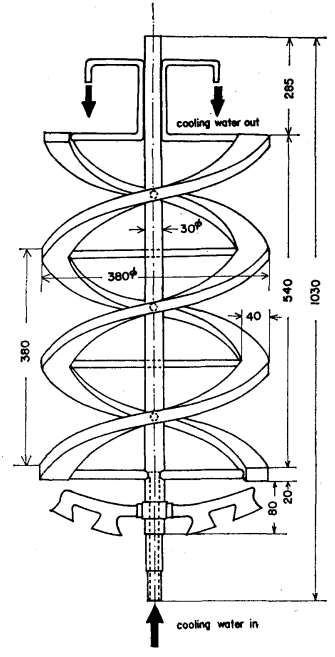

Fig. 5 Helical ribbon

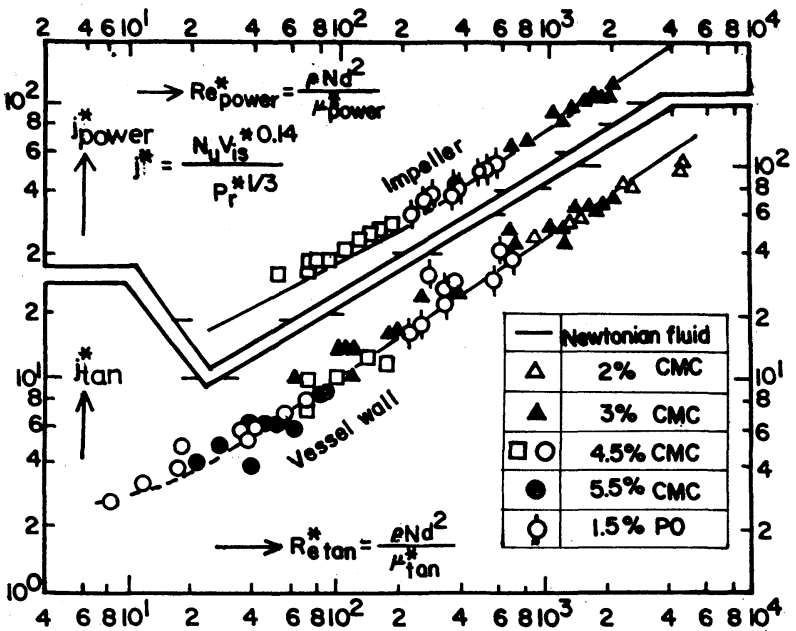

Fig. 6 Correlations of non-Newtonian heat transfer for an agitator with 2-bladed paddle $(d=20 \mathrm{~cm})$

and the flow of cooling water through the ribbon.

Table 2 gives the dimensions of the agitator.

Various concentrations of aqueous solutions of $\mathrm{CMC}$ (carboxymethylcellulose), HEC (hydroxymethycellulose), PO (polyethylene oxide) and SPA (Sodium Polyacrylate) were used as non-Newtonian fluids. CMC aqueous Newtonian fluids which have Newtonian behavior in cases of prolonged violent agitation were also used. The experimental procedures were essentially the same as described in the previous paper $^{7)}$.

\section{2 Experimental results and discussion}

(1) An agitator with 2-bladed paddle

The experimental results are shown in Figs. 6 $(d=20 \mathrm{~cm})$ and $\mathbf{7}(d=32.2 \mathrm{~cm})$. The solid lines repre-

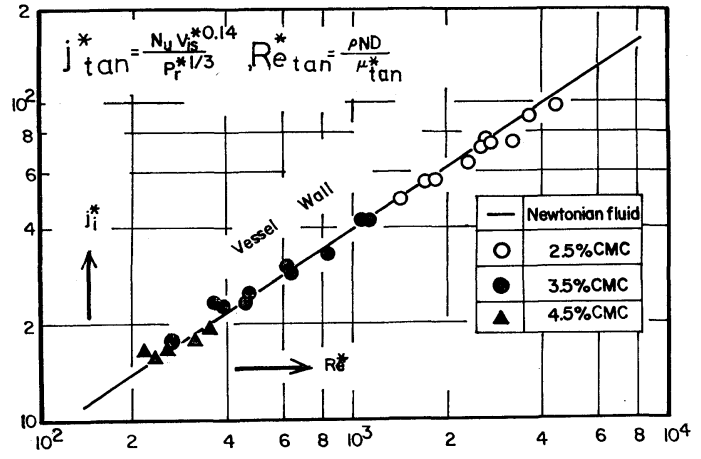

Fig. 7 Correlations of non-Newtonian heat transfer for an agitator with 2-bladed paddle $(d=32.2 \mathrm{~cm})$

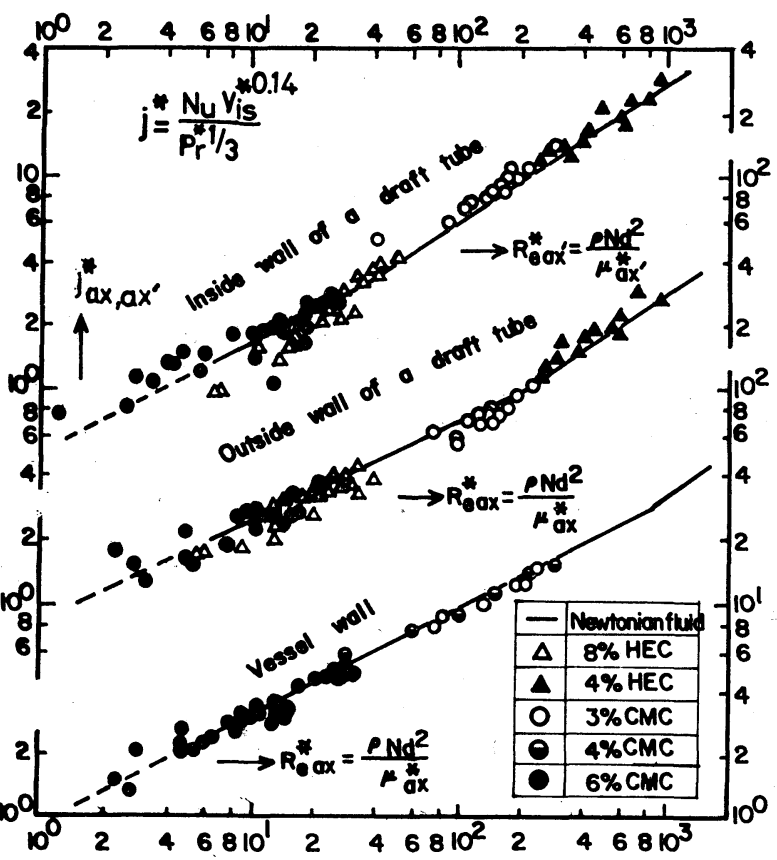

Fig. 8 Correlations of non-Newtonian heat transfer for an agitator with a helical screw in a draft tube

sent the results for Newtonian heat transfer obtained in the authors' previous paper. By using non-Newtonian viscosities in Eqs.(13) and (14), the present experimental data for non-Newtonian heat transfer could be correlated in terms of Newtonian heat transfer.

(2) An agitator with a helical screw in a draft tube

The results áre shown in Fig. 8 and indicate that the experimental data for non-Newtonian heat transfer coincide with the solid lines which represent the Newtonian heat transfer correlation given in the authors' previous paper? ${ }^{\text {) }}$ By using Eqs. (24) and (28) for the non-Newtonian viscosities, non-Newtonian heat 

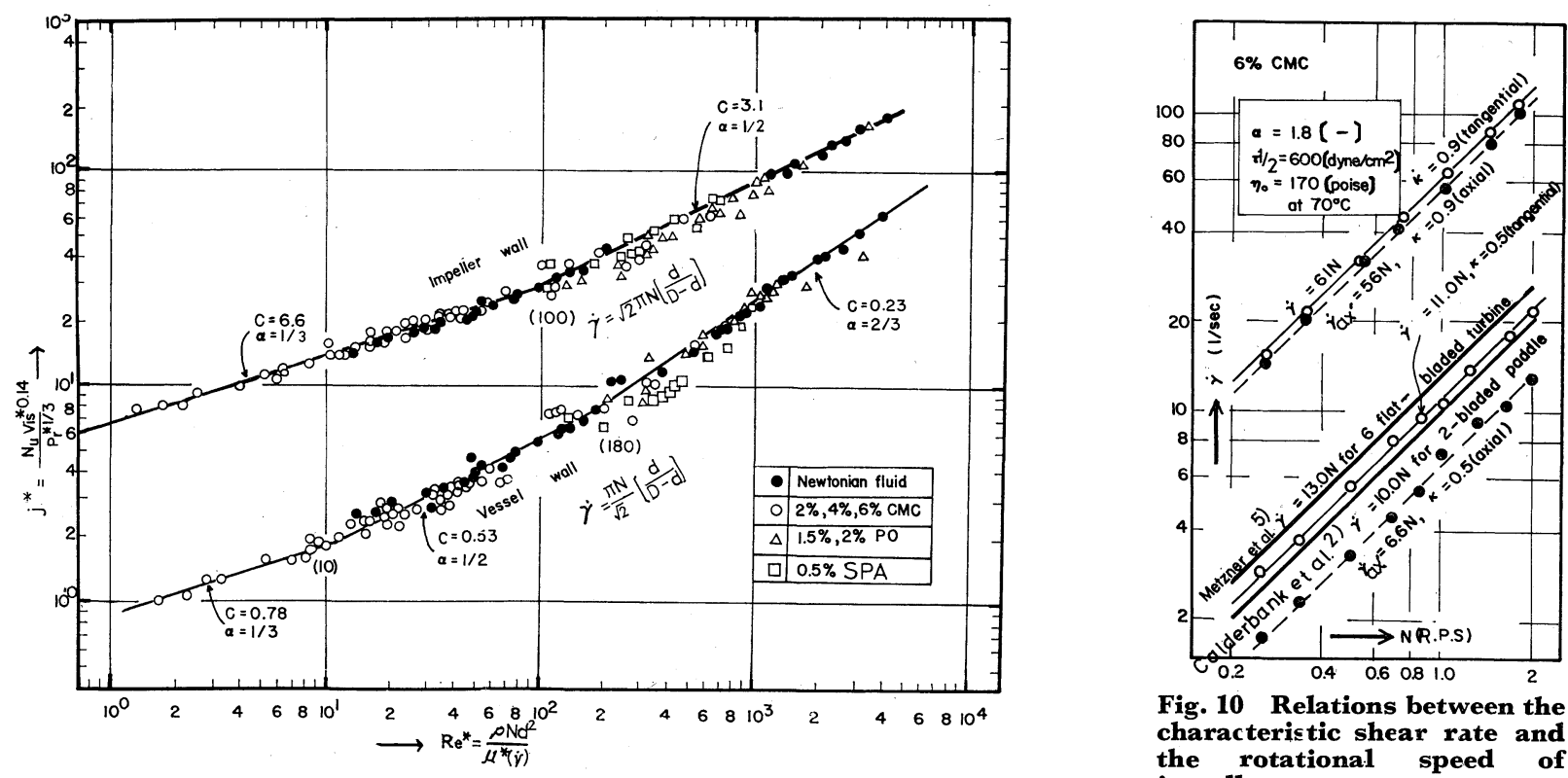

Fig. 10 Relations between the characteristic shear rate and the rotational speed of impeller

Fig. 9 Correlations of non-Newtonian heat transfer for an agitator with a helical ribbon

transfer data coincide with the authors' Newtonian heat transfer correlations.

(3) An agitator with a helical ribbon

The results are shown in Fig. 9. The solid circles represent the experimental data for Newtonian fluids. The correlation curves of the experimental data for non-Newtonian heat transfer agree well with Newtonian curves by using non-Newtonian viscosity described in 2.3. The present results deviate from the correlation by Mizushina et al..$^{9}$, probably due to the difference in geometry of the helical ribbon. The empirical constants in Eq. (1) are listed in Table 3.

\section{Discussion of Relation Between the Chara- cteristic Shear Rate and the Rational Speed of Impeller}

Some recent studies have presented the relation ${ }^{3,8,11)}$

$$
\dot{\gamma}=k N
$$

Figure 10 shows that this equation is valid for a given size of flow model. The factor $k$, however, will vary with size in geometrically similar flow systems. Therefore, it may be difficult to correlate experimental data for geometrically similar but variously sized agitators with a constant value of $k$ as has been proposed by some authors.

\section{Summary}

Studies were made of non-Newtonian heat transfer in agitated vessels using high polymer aqueous solutions such as CMC, HEG, PO and SPA. The heat transfer experiments were carried out in agitators having paddle, a helical screw in a draft tube, and a helical ribbon. The three-constant Ellis model was used to define the viscosity of non-Newtonian fluids.

\begin{tabular}{|c|c|c|c|}
\hline \multicolumn{4}{|c|}{$\begin{array}{l}\text { Table } 3 \text { Empirical constants in Eq. (1) for an agitator } \\
\text { with a helical ribbon }\end{array}$} \\
\hline Surface of heat transfer & C & $\alpha$ & $R e$ \\
\hline Helical ribbon wall & $\begin{array}{l}6.6 \\
3.1\end{array}$ & $\begin{array}{l}1 / 3 \\
1 / 2\end{array}$ & $\begin{array}{l}1 \text { to } 100 \\
100 \text { to } 4 \times 10^{3}\end{array}$ \\
\hline Jacketed vessel wall & $\begin{array}{l}0.78 \\
0.53 \\
0.23\end{array}$ & $\begin{array}{l}1 / 3 \\
1 / 2 \\
2 / 3\end{array}$ & $\begin{array}{l}1.5 \text { to } 10 \\
10 \text { to } 180 \\
180 \text { to } 4 \times 10^{3}\end{array}$ \\
\hline
\end{tabular}

By using the non-Newtonian viscosities proposed in this paper, the correlation curves for non-Newtonian heat transfer with these three typical agitators agree very well with those for Newtonian heat transfer. The present experimental correlations may be useful in industrial design since only a limited number of such studies are available so far.

\section{Nomenclature}

\begin{tabular}{|c|c|c|}
\hline$C$ & $=$ empirical constant in Eq.(1) & {$[-]$} \\
\hline$C_{p}$ & $=$ specific heat & {$\left[\mathrm{cal} / \mathrm{g}^{\circ} \mathrm{C}\right]$} \\
\hline$D$ & $=$ vessel diameter & {$[\mathrm{cm}]$} \\
\hline$D_{d i}$ & $=$ inner diameter of a draft tube & {$[\mathrm{cm}]$} \\
\hline$D_{d o}$ & $=$ outer diameter of a draft tube & {$[\mathrm{cm}]$} \\
\hline$D_{e}$ & $=$ hydraulic equivalent diameter & {$[\mathrm{cm}]$} \\
\hline$D_{l}$ & $=$ characteristic length & {$[\mathrm{cm}]$} \\
\hline$d$ & $=$ impeller diameter & {$[\mathrm{cm}]$} \\
\hline$f$ & $=$ friction factor & {$[-$} \\
\hline$h$ & $=$ heat transfer coefficient & $\mathrm{n}^{2} \cdot \mathrm{sec} \cdot{ }^{\circ} \mathrm{C}$ \\
\hline$j^{*}$ & $=N u^{*} V i s^{*} 0.14 / P r^{* 1 / 3}$ & {$[-$} \\
\hline$N$ & $=$ rotational speed of impeller & [r.p.s] \\
\hline$p$ & $=$ pitch of a helical ribbon & {$[\mathrm{cm}]$} \\
\hline$Q$ & $=$ flow rate & {$\left[\mathrm{cm}^{3} / \mathrm{sec}\right.$} \\
\hline$R$ & $=$ radius & {$[\mathrm{cm}]$} \\
\hline$r_{h}$ & $=$ hydraulic equivalent radius & [cm] \\
\hline$T$ & $=$ reduced shear stress & {[} \\
\hline$V_{0}$ & $=$ defined in Eq.(26) & {[} \\
\hline$v$ & $=$ average fluid velocity & {$[\mathrm{cm} / \mathrm{sec}]$} \\
\hline$v_{0}$ & $=$ vertically moving velocity of inner cylinder & {$[\mathrm{cm} / \mathrm{sec}]$} \\
\hline$\alpha$. & $\begin{aligned}= & \text { empirical constant in Eq.(1) or rheological } \\
& \text { constant in Ellis model }\end{aligned}$ & {$[-$} \\
\hline$\beta$ & $=$ factor & \\
\hline
\end{tabular}

$C \quad=$ empirical constant in Eq.(1)

$D_{d i} \quad=$ inner diameter of a draft tube

$=$ outer diameter of a draft tube

$=$ characteristic length

$=$ impeller diameter

riction factor

$=N u * V i s * 0.14 / P r * 1 / 3$

$=$ rotational speed of impeller

$=$ hydraulic equivalent radius

= reduced shear stress

- average fluid velocity

constant in Ellis model 


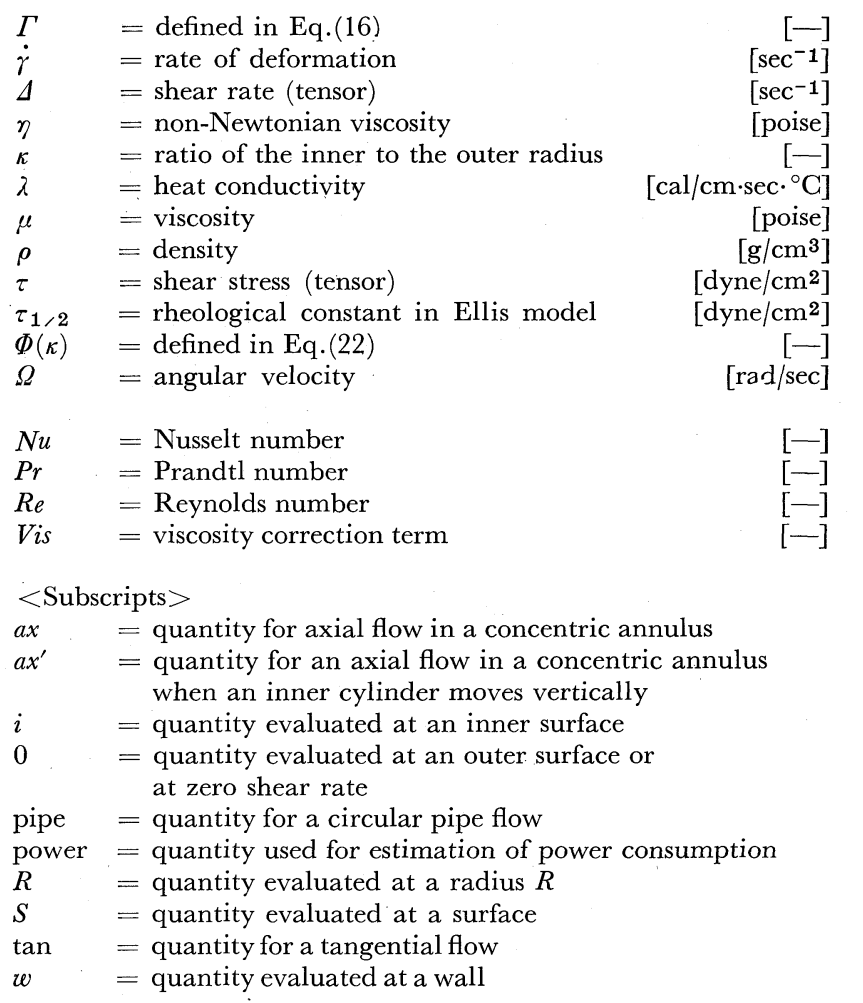

< Superscript $>$
$\quad=$ quantity for non-Newtonian fluids

\section{Literature Cited}

1) Carreau, P., G. Charest and J. L. Corneille: Can. Jour. Chem. Eng., 44, 3 (1966)

2) Calderbank, P. H. and M. B. Moo-Young: Trans. Instn. Chem. Engrs., 37, 26 (1959)

3) Gluz, M. D. and I. S. Pavlushenko: Jour. Appl. Chem. USSR, 39, 2323 (1966)

4) Hagedorn, D. and J. J. Salamone: I \& EC., Process Design \& Development, 6, 469 (1967)

5) Metzner, A. B. and R. E. Otto: AIChE J., 3, 3 (1957)

6) Mitsuishi, N. and N. Hirai: J. Chem. Eng. Japan, 2, 217 (1969)

7) Mitsuishi, N., Y. Miyairi and T. Katamine: J. Chem. Eng. Japan, 6, 410 (1973)

8) Mizushina, T., R. Ito, Y. Murakami and S. Tanaka: Kagaku Kōgaku, 30, 819 (1966)

9) Mizushina, T., R. Ito, S. Hiraoka, T. Murata and T. Yamanaka: Kagaku Kōgaku, 34, 313 (1970)

10) Nagata, S., M. Nishikawa, T. Kayama and M. Nakajima: J. Chem. Eng. Japan, 5, 187 (1972)

11) Pavlushenko, I. S. and M. D. Gluz: Jour. Appl. Chem. USSR, 39, 2146 (1966)

12) Pollard, J. and T. A. Kantyaka: Trans. Inst. Chem. Engrs., 47, T21 (1969)

13) Skelland, A. H. P. and G. R. Dimmick: $I \& E C$, Process Design \& Development, 8, 267 (1969)

\title{
DECREASE OF LIQUID FILM COEFFICIENT OF MASS TRANSFER IN PROCESS OF ABSORPTION OF SERIES OF SINGLE BUBBLE*
}

\author{
HAKARU MITSUTAKE \\ Department of Industrial Chemistry, Kyushu Sangyo \\ University, Fukuoka, Japan
}

\begin{abstract}
The overall coefficient of mass transfer based on liquid concentration, $K_{L}$, for absorption of bubbles into a liquid flowing down countercurrently has been related to the decrease in volume, area and buoyant force of bubbles in order to establish a theoretical equation for $K_{L}$. The decrease of $K_{L}$ with increase height of column has been found to be fundamentally influenced by the decrease of $V \mid A$ and the inclination $-(d / d \theta) \ln (F Z)$ of the bubbles.

This work also shows the state of counterdiffusion between carbon dioxide in bubbles and air dissolved in downflowing water, and that air in bubbles can be thought to give the gas-side resistance in the double film theory. It is one of the causes of the decrease of $K_{L}$ when the air content of bubbles increases greatly in cases where the residence time of bubbles in water is comparatively long.
\end{abstract}

\section{Introduction}

In the experiments, the instantaneous and mean

* Received on June 14, 1971

T812 福岡市東区松香台 2-327

九州産業大学工学部工業化学教室 光武 量 overall coefficient of mass transfer $K_{L}$ in absorption and the counterdiffusion between carbon dioxide in a bubble and air dissolved in water are dealt with.

The coefficient $K_{L}$ is acquired from experiments in which single bubbles of pure carbon dioxide are regularly blown into water flowing downward in a column, and the mechanism of the decrease of $K_{L}$ during absorption of carbon dioxide bubbles into liquids has been 